\title{
JGISE
}

Journal of Geospatial Information Science and Engineering

ISSN: 2623-1182 | https://jurnal.ugm.ac.id/jgise

\section{Evaluasi Pemanfaatan Citra Tegak Satelit Resolusi Tinggi untuk Percepatan Pembuatan Peta Blok Pajak Bumi dan Bangunan (PBB-P2) secara Partisipatif di Desa Triharjo, Kabupaten Bantul, DIY}

\author{
Evaluation of the Utilisation of High Resolution Ortho-Rectified Satellite Image for Accellerating the \\ Development of Participatory Land and Building Tax Block Maps (PBB-P2) in Triharjo Village, Bantul \\ Regency, DIY
}

\section{Fauzia Aristalindra, Purnama Budi Santosa, Diyono, Subaryono}

Departemen Teknik Geodesi, Fakultas Teknik, Universitas Gadjah Mada, INDONESIA

Penulis Korespondensi: Purnama Budi Santosa | Email: purnamabs@ugm.ac.id

Diterima (Received): 30/Apr/2020 Direvisi (Revised): 1/Jun/2020 Diterima untuk Publikasi (Accepted): 1/Jun/2020

\begin{abstract}
ABSTRAK
Kemajuan perkembangan teknologi penginderaan jauh dapat mendukung kebutuhan pemerintah termasuk bidang kadaster, salah satunya adalah untuk menyediakan data geospasial khususnya peta bidang tanah untuk inventarisasi nilai tanah dan pajak. Penelitian ini mencoba mengevaluasi pemanfaatan citra satelit Quickbird untuk memperbarui peta blok tanah dan bangunan (PBBP2) di Kabupaten Bantul, Daerah Istimewa Yogyakarta, Indonesia. Citra satelit yang digunakan direkam pada tahun 2014 dengan resolusi 0,6 meter dan telah dilakukan koreksi ortho-rektifikasi. Evaluasi dilakukan dengan menganalisis pemanfaatan citra Quickbird sebagai peta dasar untuk mendapatkan peta bidang tanah sesuai dengan Surat Keputusan Direktorat Pajak nomor: KEP533 / PJ / 2000. Penelitian diawali dengan melakukan digitasi batas-batas bidang tanah pada citra Quickbird untuk menghasilkan peta blok. Proses itu dilakukan oleh masyarakat melalui pemetaan partisipatif. Peta blok yang dihasilkan kemudian dibandingkan dengan peta pendaftaran tanah dari Badan Pertanahan Nasional. Evaluasi difokuskan pada keakuratan posisi bidang tanah serta luas tanah yang dihasilkan. Untuk tujuan ini peta pendaftaran tanah dianggap sebagai data referensi. Dengan memfokuskan pada 51 sampel data di Desa Triharjo, uji statistik dilakukan untuk mengevaluasi keakuratan area yang dihasilkan dari peta paket tanah digital. Hasil penelitian menunjukkan bahwa 47 sampel memenuhi persyaratan toleransi $10 \%$ sesuai dengan Keputusan Direktorat Pajak nomor KEP-533 / PJ / 2000. Selain itu, analisis uji-t dengan tingkat signifikan 5\% menunjukkan bahwa tidak ada perbedaan luas yang signifikan antara data bidang tanah hasil digitasi dengan peta pendaftaran tanah. Berdasarkan hasil tersebut, disimpulkan bahwa citra QuickBird yang sudah dilakukan proses ortho rektifikasi dapat digunakan sebagai dasar pembuatan peta blok pajak bumi dan bangunan (PBB-P2).
\end{abstract}

Kata Kunci: peta blok, paja bumi dan bangunan, Quickbird

\begin{abstract}
The recent advances of remote sensing technology development can support government needs including cadastral related purposes. One of the purposes is to supply geospatial data especially land parcel maps for land and tax value inventory. This research tries to evaluate the utilization of Quickbird Satellite image for updating land and building (PBB-P2) block maps in Bantul Regency, Yogyakarta Province of Indonesia. The image was recorded in 2014 with resolution of 0.6 meter and has been ortho-rectified. Evaluation is conducted by analyzing the utilization of the image as the base map for deriving land parcel maps according to the Decree of Tax Director General number: KEP-533/PJ/2000. The process was firstly done by digitizing land parcel boundaries on Quickbird image to produce block maps. The process was done by the community through participatory mapping. The resulting block maps then were compared with land registration map from National Land Agency. The evaluation was focused on the accuracy of land parcel position as well as the resulting land areas. For this purpose the land registration map is regarded as the reference data. By focusing on the 51 sample data in Triharjo Village, statistical test was conducted to evaluate the accuracy of the resulting areas of the digitized land parcel map. The results show that 47 samples comply with a tolerance requirement of 10\% according to the Decree of Tax Directorate number KEP-533/PJ/2000'. In addition, the t-test analysis with a significant level of 5\% indicates that there is no significant difference of area between the digitized land parcel data with land registration map. Based on the results, it is concluded that ortho-rectified QuickBird image is sufficient for producing of land and building tax (PBB-P2) block maps.
\end{abstract}

Keywords: block map, land and building tax, Quickbird

(c) Author(s) 2020. This is an open access article under the Creative Commons Attribution-ShareAlike 4.0 International License (CC BY-SA 4.0). 


\section{Pendahuluan}

Penginderaan jauh menurut Lillesand, dkk. (2014) adalah ilmu dan seni untuk memperoleh informasi tentang objek, daerah atau fenomena melalui analisis data yang diperoleh dengan menggunakan alat tanpa kontak langsung terhadap objek, daerah atau fenomena yang dikaji. Teknologi penginderaan jauh telah berkembang pesat saat ini, salah satunya didukung dengan inovasi di bidang teknologi satelit. Di bidang teknologi satelit, beberapa perusahaan komersil telah meluncurkan satelit penginderaan jauh dengan resolusi tinggi pada akhir tahun 1990an, salah satunya adalah QuickBird dengan resolusi 0,6 m yang diluncurkan oleh Digital Globe pada tahun 2001

Penginderaan jauh dapat dimanfaatkan untuk berbagai keperluan, diantaranya untuk kadaster, klasifikasi penggunaan dan penutup lahan, kebencanaan, change detection, dan pengelolaan pesisir (Santosa, 2016; Lillesand, dkk., 2014). Beberapa penelitian juga menunjukkan bahwa citra satelit resolusi tinggi dapat dimanfaatkan untuk pembuatan peta skala besar (Ali dkk, 2012; Alkan dan Marangoz, 2009; Sulistyawati dkk 2018). Produk penginderaan jauh juga digunakan di beberapa instansi pemerintah untuk menjalankan program kerjanya secara efektif, termasuk dalam bidang pertanahan seperti pembaruan peta kadaster (Ali dkk, 2012), serta pemanfaatan citra satelit IKONOS untuk pembuatan peta blok PBB (Sulistyowati, 2003).

Salah satu instansi pemerintahan yang menggunakan penginderaan jauh adalah Badan Keuangan dan Aset Daerah. Penginderaan jauh di instansi ini digunakan dalam bidang kadaster pada pembuatan peta blok untuk pengelolaan dan pemungutan Pajak Bumi dan Bangunan Perdesaan dan Perkotaan (PBB-P2). Peta blok adalah peta yang menggambarkan suatu zona geografis yang terdiri atas sekelompok objek pajak yang dibatasi oleh batas alam dan/atau buatan manusia yang bersifat permanen/tetap untuk kepentingan pengenaan pajak bumi dan bangunan dalam satu wilayah administrasi pemerintahan desa/kelurahan (Al-Vatia \& Djojomartono, 2019). PBB-P2 menurut Undang-Undang Nomor 28 Tahun 2009 merupakan pajak yang diambil atas objek pajak yang yang berupa tanah dan bangunan yang melekat di atas tanah dari subjek pajak yang merupakan orang atau badan yang mempunyai suatu hak atas tanah, dan atau memperoleh manfaat atas tanah atau bangunan kecuali pada kawasan yang digunakan untuk usaha perkebunan, perhutanan dan pertambangan.

Pembuatan peta blok PBB-P2 dapat dilakukan dengan berbagai metode diantaranya pengukuran secara terestris, fotogrametri, serta dengan pemanfaatan citra satelit. Pengukuran secara terestris dan fotogrametri memerlukan waktu yang lama dan biaya yang cukup mahal sehingga diperlukan metode lain yang lebih cepat dengan biaya yang terjangkau (Santosa dkk 2016). Oleh karena itu, pemanfaatan citra satelit dengan resolusi tinggi perlu dilakukan karena memiliki kelebihan pemrosesan data mudah, cepat dan biaya yang cukup terjangkau. Pendekatan partisipatif masyarakat bisa diterapkan untuk meningkatkan kualitas pemetaan (Aditya dkk, 2020). Penggunaan citra QuickBird sebagai data dalam pemetaan skala besar sudah banyak digunakan karena pemrosesannya mudah dan cepat serta biaya yang diperlukan cukup terjangkau (Rudianto, 2010).

Kegiatan penelitian pemanfaatan citra satelit resolusi tinggi QuickBird untuk pembuatan peta skala besar telah banyak dilakukan, diantaranya oleh Ali, dkk. (2012), serta Alkan dan Marangoz (2009). Ali dkk. (2012) melakukan penelitian pembaharuan peta kadaster menggunakan data remote sensing dan hasuilnya dapat mengurangi waktu dan biaya yang diperlukan. Alkan dan Marangoz (2009) melakukan penelitian yang serupa dengan memanfaatkan citra QuiuckBird untuk membuat peta kadastral. Hasilnya sesuai apabila digunakan dalam pembuatan peta kadaster, namun pada citra ini masih terdapat bayangan dari bangunan sehingga mempengaruhi identifikasi objek. Penggunaan citra QuickBird perlu dilakukan evaluasi sebelum digunakan untuk pembuatan peta blok PBB-P2, khususnya pada evaluasi aspek luas bidang yang diatur pada Surat Keputusan Dirjen Pajak Nomor : 533/PJ/2000 yaitu dengan maksimal selisih prosentase $10 \%$ dimana ketelitian luas dihitung dari selisih antara luasan di peta digital dengan luasan pada data atribut peta blok PBB-P2 (Direktorat Jenderal Pajak, 2000).

Pada penelitian ini dilakukan evaluasi nilai luas objek PBB (bidang-bidang tanah) hasil digitasi pada citra QuickBird yang digunakan untuk membuat peta blok PBB-P2 dengan merujuk pada Surat Keputusan Direktorat Jenderal Pajak Nomor KEP522/PJ/2000 (Aristalindra, 2019). Selanjutnya untuk acuan evaluasi luasan objek PBB tersebut digunakan luas bidang-bidang tanah pada peta pendaftaran tanah yang dibuat sesuai PMNA No 3 Tahun 1997. Peta pendaftaran menurut pasal 1 PP Nomor 24 tahun 1997 adalah peta yang menggambarkan bidang atau bidang-bidang tanah yang batas-batasnya telah ditetapkan oleh pejabat yang berwenang untuk keperluan pembukuan tanah Tujuan dibuatnya Peta pendaftaran adalah untuk memberikan kepastian hukum kepada pemegang hak atas tanah, menyediakan informasi kepada pihak-pihak yang berkepentingan serta agar dapat terselenggara tertib administrasi pertanahan.

\section{Data dan Metodologi}

\subsection{Data dan Lokasi}

Data yang digunakan dalam penelitian ini berupa data spasial dan data nonspasial yang berlokasi di Desa Triharjo, Kecamatan Pandak, Kabupaten Bantul, Daerah Istimewa Yogyakarta (D.I.Y). Data spasial yang digunakan adalah peta pendaftaran tahun 2015 dan data Citra Tegak Satelit Resolusi Tinggi (CTSRT) QuickBird tahun 2014. Data citra QuickBird sebagai data utama yang digunakan untuk membuat peta blok PBB-P2. CTSRT tersebut merupakan produk Badan Informasi Geospasial (BIG) dan diperoleh dari Dinas Pertanahan dan Tata Ruang (DPTR) Kabupaten Bantul. Data CTSRT disajikan pada Gambar 1.

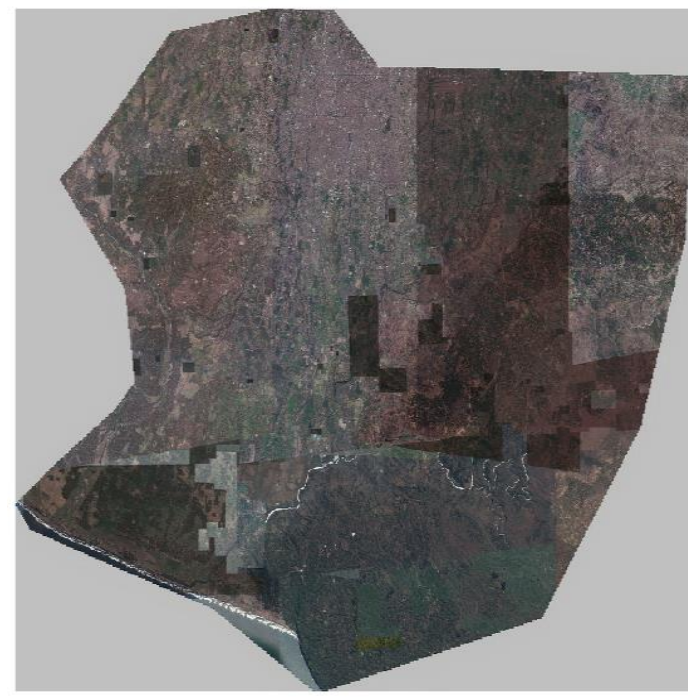

Gambar 1. Citra Tegak Satelit Resolusi Tinggi QuickBird (Sumber: DPTR Kabupaten Bantul)

Peta pendaftaran (Gambar 2) digunakan sebagai data acuan untuk melakukan evaluasi luas bidang tanah sebagai objek PBB Peta ini merupakan produk dari instansi Agraria Tata Ruang/Badan Pertanahan Nasional (ATR/BPN) Kabupaten Bantul 
dan diperoleh dari Badan Keuangan dan Aset Daerah (BKAD) Kabupaten Bantul dalam format shapefile.

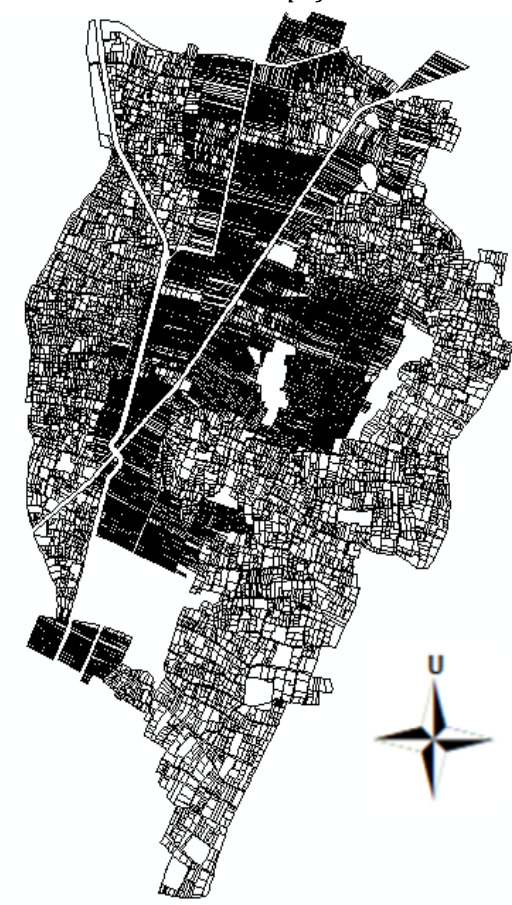

Gambar 2. Peta pendaftaran Desa Triharjo (Sumber: BPN Kabupaten Bantul)

Data nonspasial yang digunakan adalah data atribut peta blok PBB-P2 yang berupa Surat Pemberitahuan Objek Pajak (SPOP). SPOP merupakan data tabular dengan format xls yang diperoleh dari Badan Keuangan dan Aset Daerah (BKAD) Kabupaten Bantul yang salah satunya berisi nilai luas bidang objek pajak. Data ini digunakan sebagai data pembanding pada evaluasi peta blok PBB hasil digitasi dari CTSRT.

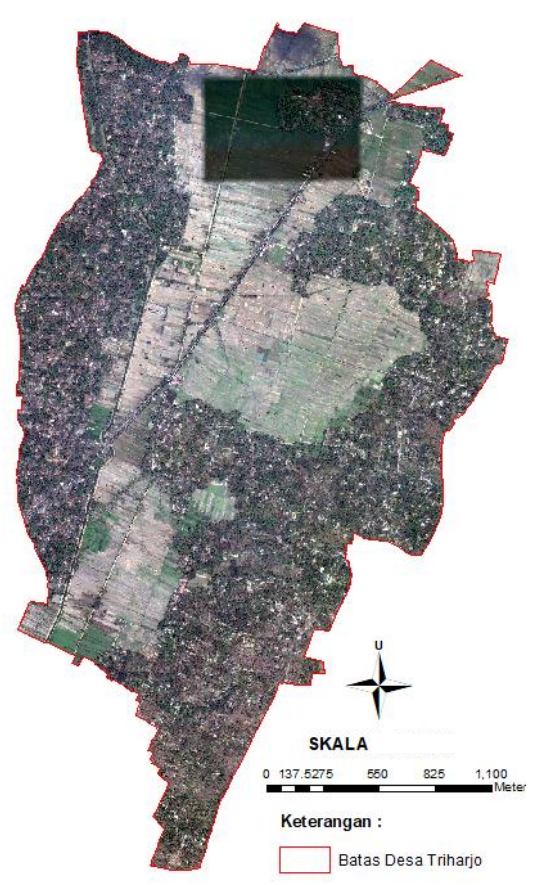

Gambar 3. Hasil pemotongan citra QuickBird (Sumber: DPTR Kabupaten Bantul dan hasil pengolahan)

\subsection{Metodologi \\ Pemotongan Citra}

Pemotongan citra dilakukan dengan memotong citra Kabupaten Bantul menjadi hanya pada daerah penelitian saja yaitu Desa Triharjo. Pemotongan dilakukan dengan menggunakan perangkat lunak ArcMap berdasarkan batas desa yang diperoleh dari peta pendaftaran Desa Triharjo.. Hasil pemotongan CTSRT dapat dilihat pada Gambar 3.

\section{Pemilihan Sampel Bidang}

Pemilihan sampel bidang tanah dilakukan oleh bersama dengan kepala dusun setempat secara partisipatif untuk menghemat waktu penelitian namun tetap dapat merepresentasikan keseluruhan data. Pemilihan sampel ini dilakukan dengan teknik cluster / area sampling yaitu dengan menentukan suatu luasan area tertentu dimana pada penelitian ini adalah nomor blok yang akan dilakukan sampling. Selanjutnya dari setiap blok tersebut diambil beberapa sampel bidang tanah. Pada pemilihan blok diambil 4 blok sebagai sampel, yaitu pada blok 001 yang merupakan blok pada Dusun Siyangan, blok 009 pada Dusun Juwono, blok 038 pada Dusun Jigudan, dan blok 043 pada Dusun Jalakan (lihat Gambar 4 untuk sebaran blok, dan Gambar 5 untuk sebaran sampel bidang tanah pada Blok 043). Pada setiap sampel masing-masing diambil 10-15 bidang tanah sebagai sampel dengan teknik sampel berjatah (quota sampling). Teknik sampel berjatah adalah pengambilan sampel yang dilakukan berdasarkan pertimbangan peneliti dan besar serta kriteria sampel telah ditentukan terlebih dahulu (Nasution, 2003). Jumlah populasi (N) bidang pada peta pendaftaran tanah di Desa Triharjo sebanyak 12.356 buah, sehingga nilai sampel yang digunakan dalam penelitian dapat dihitung menggunakan persamaan slovin (1) berikut (Tejada and Punzalan, 2012):

$$
n=\frac{N}{1+N e^{2}}=\frac{12.356}{1+12.356 \times(0,1)^{2}}=99
$$

Berdasarkan persamaan (1) di atas, maka jumlah sampel yang harus diambil agar bisa merepresentasikan populasi (keseluruhan data) adalah 99 buah sampel. Namun, pada penelitian ini hanya digunakan sampel sebanyak 51 buah. Hal ini disebabkan karena proses identifikasi batas bidang dan digitasi di atas citra QuickBird dilakukan secara partisipatif bersama para kepala dusun setempat mengalami beberapa kendala, seperti keterbatasan waktu, kendala lokasi yang sulit dijangkau, serta keterbatasan informasi para kepala dusun terhadap bidang tanah di wilayahnya.

\section{Interpretasi dan Digitasi Batas Bidang}

Setelah memilih bidang tanah yang dijadikan sampel, selanjutnya sampel-sampel bidang tanah tersebut diinterpretasikan batas bidangnya pada citra. Proses interpretasi batas bidang dilakukan secara partisipatif bersama para kepala kepala dusun setempat karena interpretasi citra diketahui lebih baik melalui keakraban dengan lingkungan dan objek yang diamati (Lillesand, dkk., 2014). Proses interpretasi dilakukan agar titik-titik batas bidang dapat dilakukan digitasi pada citra QuickBird. Hasil interpretasi batas bidang selanjutnya didigitasi di lapangan (lokasi survei) bersama kepala dusun setempat.

Proses interpretasi titik batas bidang tanah tidak hanya dilakukan di atas citra, tetapi juga dilakukan identifikasi di lapangan, khususnya untuk bidang-bidang tanah yang batasnya tidak terlihat di atas citra, dan tidak dapat diinterpretasi secara visual. Kondisi ini biasanya terjadi pada bidang-bidang tanah yang titik batasnya tidak terlihat karena tertutupi oleh vegetasi lebat 
(pepohonan yang rapat) sehingga sulit ditentukan batas bidangnya. Oleh karena itu posisi titik batas bidangnya dicari secara langsung di lapangan untuk mempermudah interpretasi titik batas bidang di atas citra. Setelah mengetahui titik batas bidang di lapangan, titik batas bidang tersebut didigitasi di atas citra bersama dengan kepala dusun.

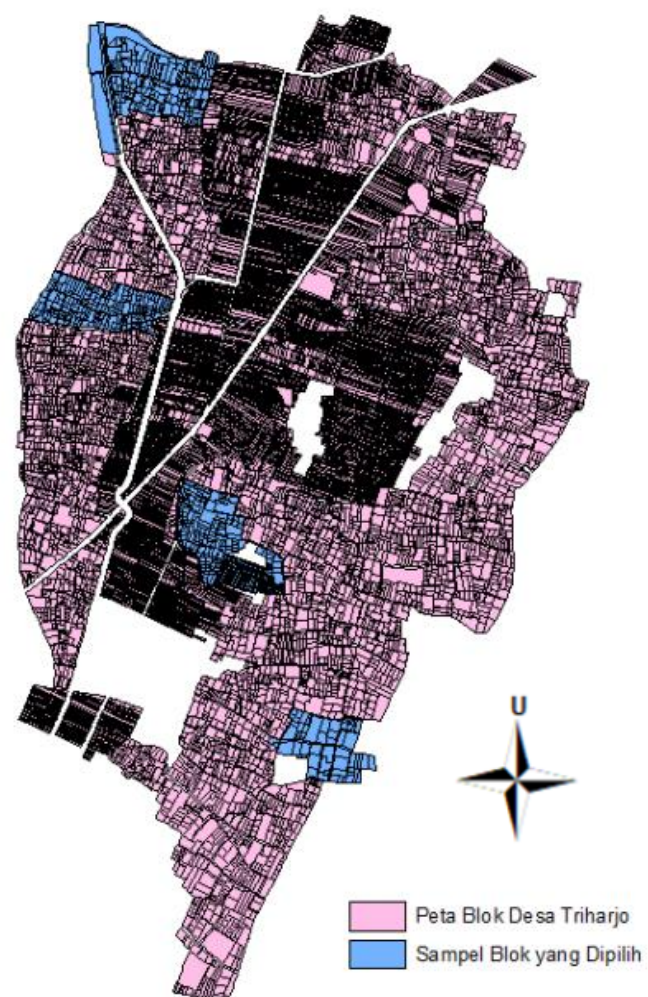

Gambar 4. Lokasi blok yang dipilih sebagai sampel (Sumber: BKAD Kabupaten Bantul dan hasil pengolahan).

\section{Perhitungan Luas Bidang Tanah}

Perhitungan luas bidang tanah pada hasil digitasi citra QuickBird dan peta pendaftaran tanah digital dilakukan menggunakan fungsi 'Calculate Geometry' pada perangkat lunak ArcMap. Luas sampel bidang tanah pada attribute table kemudian dikonversi menjadi tabel excel menggunakan Conversion Tools yang ada pada ArcToolbox. Konversi tabel ini dilakukan agar hasil hitungan luas bidang tanah hasil digitasi dari CTRST dan peta pendaftaran dapat dibaca dan dilakukan analisis perbedaan luas lebih lanjut menggunakan perangkat lunak Ms. Excel.

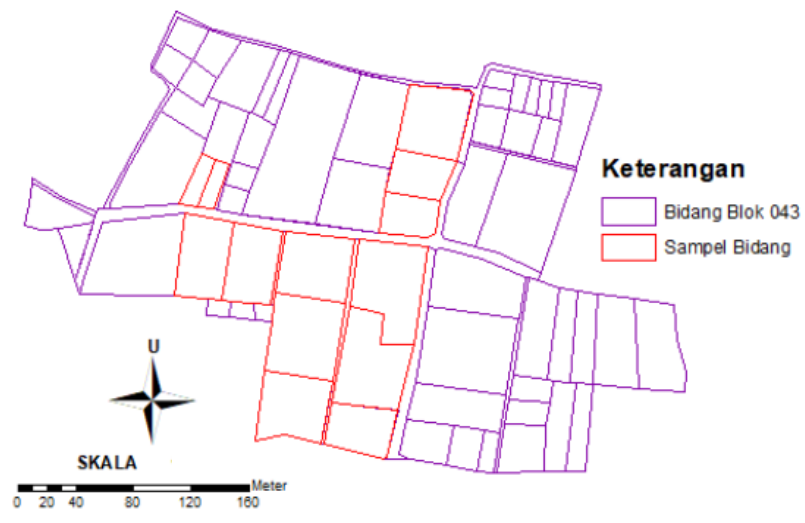

Gambar 5. Sebaran sampel bidang tanah pada Blok 043 (Sumber: BKAD Kabupaten Bantul dan hasil pengolahan).

\section{Analisis Hasil}

Hasil dari pengolahan perangkat lunak Ms Excel dan perhitungan statistik maupun syarat toleransi beda luas kemudian dilakukan analisis. Analisis hasil penelitian ini meliputi analisis perbandingan luas sampel bidang tanah, analisis hasil uji selisih luas berdasarkan KEP-533/PJ/2000, analisis hasil uji selisih luas berdasarkan PMNA No 3 Tahun 1997, serta analisis hasil uji statistik perbedaan luas menggunakan uji t. Uji statistik t merupakan pengujian yang digunakan untuk menguji hipotesis nilai rata-rata antara dua set data. Pada pengujian hipotesis menggunakan uji t dua pihak berlaku ketentuan bahwa Hipotesis Nol (Ho) tidak terdapat perbedaan yang signifikan antara luas bidang tanah hasil digitasi citra CTSRT terhadap data luas acuan, sedangkan Hipotesis Alternatif (Ha) terdapat perbedaan yang signifikan antara luas bidang tanah hasil digitasi citra QuickBird terha

dap data luas acuan. Hipotesis Nol (Ho) diterima dan Hipotesis Alternatif ( $\mathrm{Ha}$ ) ditolak apabila nilai t hitung lebih kecil dari t tabel, sedangkan Hipotesis Nol (Ho) ditolak dan Hipotesis Alternatif (Ha) diterima apabila nilai $t$ hitung lebih besar dari $t$ tabel. Untuk menguji suatu hipotesis dilakukan dengan mencari nilai t hitung menggunakan persamaan (2) berikut (Watters, 2008) :

$$
t_{\text {hitung }}=\frac{\Delta L_{\text {rata }- \text { rata }}-\delta}{S \Delta L / \sqrt{n}}
$$

Keterangan :

$\Delta L_{\text {rata-rata }}$

$\delta$

$S \Delta L$

$n$

$$
\begin{aligned}
& \text { : rata-rata selisih luas dari dua set data }\left(\mathrm{m}^{2}\right) \\
& \text { : nilai beda luas yang diharapkan }(\mathrm{nol}) \\
& \text { : simpangan baku selisih luas }\left(\mathrm{m}^{2}\right) \\
& \text { : jumlah data }
\end{aligned}
$$

\section{Hasil dan Pembahasan}

\subsection{Hasil Digitasi Sampel Bidang Tanah}

Deliniasi batas bidang tanah dihasilkan melalui tahapan proses digitasi baik dilakukan di atas citra mauapun di lapangan, melalui pendekatan partisipatif bersama para kepala dusun dan pemilik tanah.

Pendekatan partisipatif ini dirasakan cukup efektif dan efisien, apalagi kalau dibandingkan dengan proses deliniasi yang dilakukan oleh staf kantor BKAD maupun peneliti. Hal ini karena proses delniasi yang dilakukan melibatkan pengetahuan lokal (local knowledge) dari masyarakat setempat yang lebih memahami kondisi setempat, terutama dalam mengidentifikasi lokasi bidang tanah, posisi batas bidang tanah, serta informasi mengenai pemilik tanah. Melalui pendekatan partisipatif ini, ada beberapa nilai positif yang diperoleh: (1) waktu lebih efisien, (2) informasi lebih akurat, (3) penolakan masyarakat terhadap kegiatan ini bisa diminimalisir. Namun demikian, ada juga beberapa kendala yang dihadapi, yaitu: (1) perlu koordinasi yang baik dengan masyarakat agar agenda kegiatan bisa dilakukan dengan baik, (2) perlu ektra usaha untuk melakukan transfer pengetahuan mengenai prosedur kerja yang dilakukan.

Selanjutnya, hasil deliniasi batas bidang tanah dilakukan proses digitasi pada citra QuickBird sehingga diperoleh data spasial bidang tanah dengan tipe poligon yang disimpan dalam format shapefile. Beberapa contoh bidang tanah hasil digitasi di atas citra Quickbiid ini dalam dilihat pada Gambar 6, Gambar 7, Gambar 8, dan Gambar 9.

Hasil digitasi berupa fitur polygon digunakan agar dari hasil digitasi batas bidang tersebut dapat dilakukan perhitungan luas sampel bidang tanah. Dalam melakukan digitasi sampel bidang 
bersama kepala dusun, digitasi batas bidang dilakukan dengan arahan yang diberikan oleh kepala dusun untuk menentukan lokasi titik batas bidang yang kemudian didigitasi menjadi sebuah polygon sampel bidang.

Untuk batas bidang yang tertutup vegetasi, dilakukan identifikasi titik batas bidang menggunakan orientasi objek-objek lain yang ada di sekitar titik batas bidang tersebut dengan arahan kepala dusun setempat. Sebagai contoh apabila pada titik batas bidang yang tertutup vegetasi disekitarnya terdapat atap atau jalan, maka identifikasi titik dilakukan dengan memperkirakan jarak antara objek lain dengan titik batas bidang pada kondisi lapangan dan pada cira QuickBird dengan bantuan arahan kepala dusun setempat.

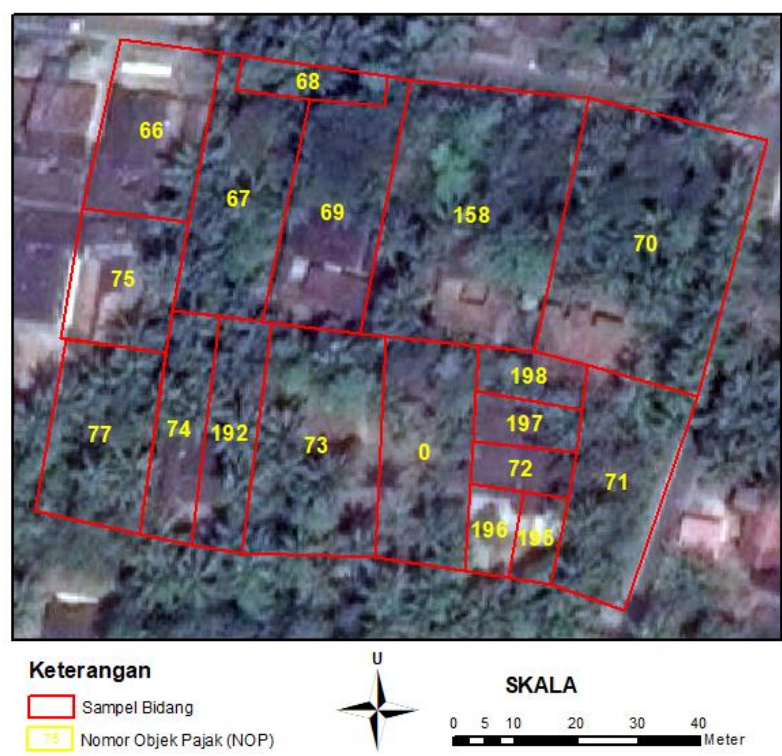

Gambar 6. Hasil digitasi sampel blok 001

Pada Blok 001 (Gambar 6) terlihat bahwa titik-titik batas bidang banyak yang tertutup oleh vegetasi pepohonan, seperti pada bidang dengan Nomor Objek Pajak (NOP) 77, 74, 192, 73, 67 lebih sulit diidentifikasi titik batas bidangnya sehingga perlu lebih teliti dalam penentuan 35 titik batas bidangnya, selain itu penentuan titik batas bidang juga dilakukan dengan memperhatikan bentuk sampel bidang pada peta pendaftaran Namun pada sampel-sampel bidang yang berbatasan dengan jalan dan seperti bidang dengan NOP 71, 70, 158 lebih mudah dilakukan identifikasi batas bidangnya karena mengikuti bentuk objek jalan dan objek jalan lebih mudah diidentifikasi karena merupakan garis lurus panjang dengan warna abu-abu tebal. Selain berbatasan dengan objek jalan, sampel-sampel bidang yang berbatasan dengan objek rumah juga lebih mudah untuk diidentifikasi, seperti pada bidang dengan NOP 66, 70 dan 75 karena atap-atap objek rumah ini terlihat dan dapat diidentifikasi pada citra.

Pada Blok 009 (Gambar 7) terlihat bahwa sebagian besar titiktitik batas sampel bidang tertutup oleh vegetasi pepohonan, seperti pada bidang dengan Nomor Objek Pajak (NOP) 62, 63, 68, $69,70,92,93,94,95,96$, dan 97 sehingga pada interpretasi titiktitik batas sampel bidang di atas citra pada Blok 009 cukup sulit dilakukan. Untuk mengatasi permasalahan ini, dilakukan survei lapangan posisi titik-titik batas sampel bidang secara langsung di lapangan dengan dibantu masyarakat sekitar untuk menunjukkan titik batasnya.
Pada Blok 038 (Gambar 8) dapat dilihat bahwa sebagian besar titik batas sampel bidang tidak tertutup oleh vegetasi pepohonan namun titik-titik batas sampel bidang tersebut berbetasan dengan objek rumah sehingga lebih mudah dilakukan identifikasi titiktitik batas bidangnya karena atap-atap objek rumah ini terlihat dan dapat diidentifikasi citra.

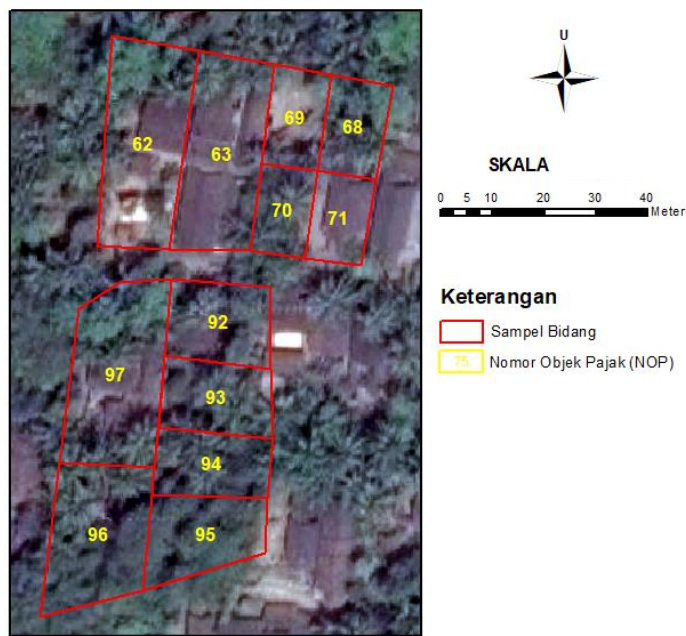

Gambar 7. Hasil digitasi sampel blok 009

Dalam melakukan digitasi sampel bidang, perlu diperhatikan ukuran-ukuran panjang dan luasan agar hasil digitasi tidak menyimpang terlalu jauh dari data acuan. Contoh perhitungn ukuran panjang adalah pada lebar jalan yang diapit oleh bidang dengan Nomor Objek Pajak 18, 17, 418, 19 dan 273 diketahui oleh kepala dusun selebar 3 meter sehingga diukur menggunakan tool 'measurement' yang tersedia pada perangkat lunak dan dapat digunakan sebagai acuan dalam menentukan titik-titik batas bidang pada sampel bidang 18, 17, 418, 19 dan 273.

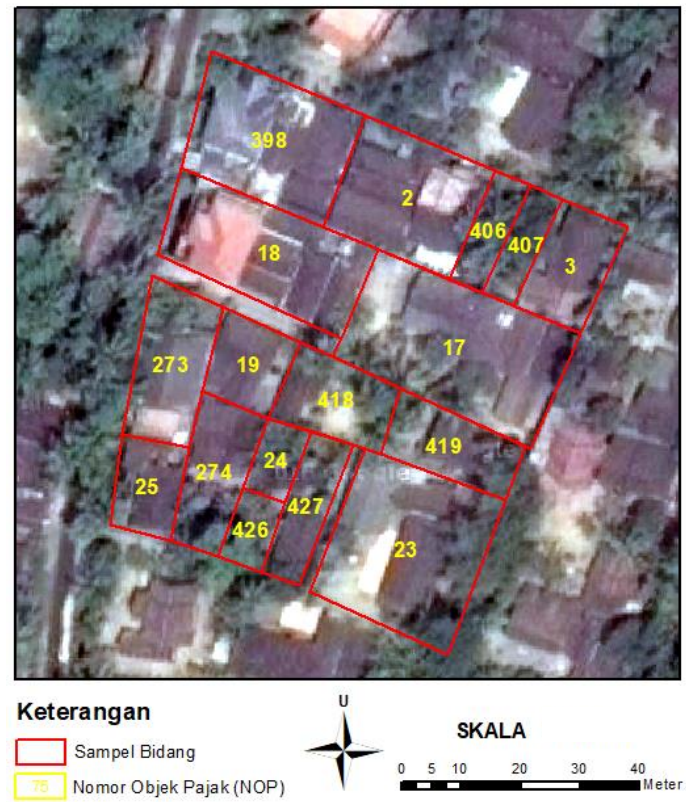

Gambar 8. Hasil digitasi sampel blok 038

Dari 13 sampel bidang pada Blok 043 (Gambar 9), 4 sampel bidang tidak memiliki NOP sehingga tidak terdapat pada data 
atribut Surat Pemberitahuan Objek Pajak (SPOP). Dan sebanyak 4 bidang sudah memiliki NOP $(0069,0070,0205$, dan 0206) namun pada SPOP 39 belum tercantum nilai luas bidangnya. Pada bidangbidang yang belum memiliki nilai luas pada SPOP ini tidak digunakan dalam melalukan analisis syarat toleransi selisih luas dan analisis uji statistik.

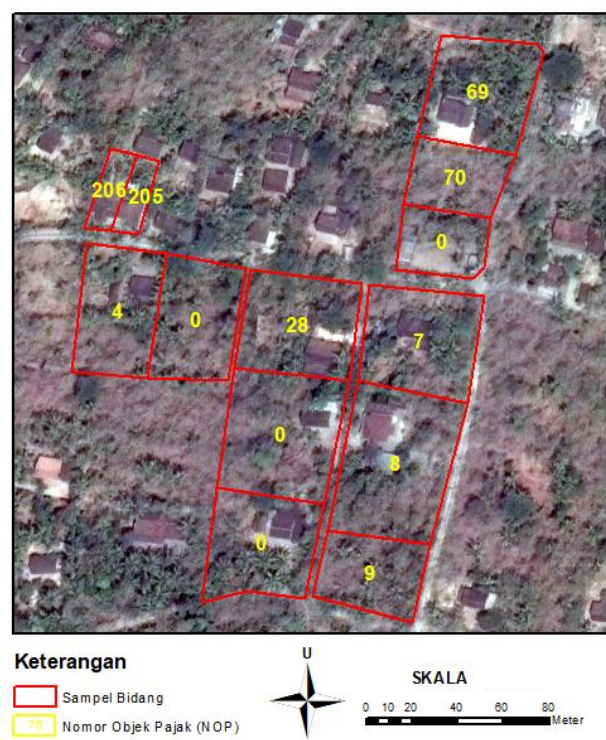

Gambar 9. Hasil digitasi sampel blok 043

Dalam proses identifikasi batas bidang tanah menggunakan citra satelit maupun foto udara, salah satu problem utama yang dihadapai dengan permasalahan dalam mengidentifikasi batas bidang tanah pada lokasi yang tertutup vegetasi. Di dalam penelitian ini permasalahan tersebut juga dihadapi. Alternatif yang diterapkan di dalam penelitian ini adalah dengan mendatangi lokasi bidang tanah tersebut bersama masyarakat untuk mengidentifikasi posisi titik-titik batas bidang tanah, selanjutnya menentukan posisi titik batas tersebut di atas citra satelit. Jadi metode alternatif seperti metode suplesi tidak diterapkan di dalam penelitian ini.

\subsection{Evaluasi Menurut SK KEP-533/PJ/2000}

Menurut SK Dirjen Pajak Nomor KEP-533/PJ/2000, prosentase selisih luas antara peta digital (hasil digitasi CTSRT) dengan luas referensi tidak boleh lebih dari 10\%. Perhitungan syarat toleransi tersebut dilakukan menggunakan persamaan (3) Evaluasi menurut syarat toleransi ini dilakukan antara hasil digitasi dengan luas atribut peta blok dan antara hasil digitasi dengan peta pendaftaran. Evaluasi nilai luas hasil digitasi citra QuickBird terhadap data atribut peta blok (SPOP) disajikan pada Tabel 1. Evaluasi ini dilakukan sebagai perbandingan evaluasi luas pada evaluasi terhadap luas referensi peta pendaftaran menurut SK Dirjen Pajak. Evaluasi nilai luas hasil digitasi citra QuickBird terhadap peta pendaftaran tanah disajikan pada Tabel 2 .

$$
\frac{L_{2}-L_{1}}{L_{1}} \times 100 \%<10 \%
$$

Keterangan :

$L_{1}$ : luas bidang pada data referensi

$L_{2}$ : luas bidang hasil digitasi citra QuickBird
Tabel 1. Hasil evaluasi terhadap SPOP berdasarkan KEP-533/PJ/2000

\begin{tabular}{|l|r|}
\hline Jumlah Data & 51 Bidang \\
\hline Prosentase Minimum & $0.029 \%$ \\
\hline Prosentase Maksimum & $2068.873 \%$ \\
\hline Rata-Rata Prosentase & $65.516 \%$ \\
\hline Syarat Toleransi & $10 \%$ \\
\hline Jumlah Bidang Diterima & 30 Bidang \\
\hline Jumlah Bidang Ditolak & 21 Bidang \\
\hline
\end{tabular}

Nilai prosentase selisih luas pada setiap sampel bidang tanah pada syarat toleransi ini dinyatakan diterima apabila nilainya tidak lebih dari $10 \%$ dan ditolak apabila nilainya lebih besar dari $10 \%$. Hali dari pengujian menunjukkan terdapat 30 sampel bidang yang dan terdapat 21 bidang tanah yang ditolak. Sampel bidang hasil digitasi citra QuickBird yang ditolak pada syarat toleransi ini disebabkan adanya kesalahan identifikasi titik batas bidang tanah, seperti pada bidang tanah dengan NOP $66,67,68,73,77,158$ dan 198 pada blok 001. Pada blok ini, titik-titik batas bidang banyak yang tertutup oleh vegetasi pepohonan sehingga sulit ditentukan batas bidangnya. Selain identifikasi titik batas bidang terdapat nilai luas tanah yang sangat berbeda pada hasil digitasi citra QuickBird dengan luas pada SPOP yaitu pada bidang dengan NOP 158 blok 001. Pada bidang ini, luas yang dihasilkan dari hasil digitasi sebesar 1192,88 $\mathrm{m}^{2}$ namun pada SPOP hanya tertera 55 $\mathrm{m}^{2}$. Perbedaan luas ini dapat dicek kembali luasnya menurut luas pada peta pendaftaran, dimana luas yang mendekati luas dari peta pendaftaran adalah nilai luas dari hasil digitasi citra QuickBird.

Tabel 2. Hasil uji terhadap luas peta pendaftaran berdasarkan KEP-533/PJ/2000

\begin{tabular}{|l|r|}
\hline Jumlah Data & 51 Bidang \\
\hline Prosentase Minimum & $0,050 \%$ \\
\hline Prosentase Maksimum & $28,259 \%$ \\
\hline Rata-Rata Prosentase & $3,312 \%$ \\
\hline Syarat Toleransi & $10 \%$ \\
\hline Jumlah Bidang Diterima & 47 Bidang \\
\hline Jumlah Bidang Ditolak & 4 Bidang \\
\hline
\end{tabular}

Pengujian luas sampel bidang hasil digitasi citra QuickBird yang dibandingkan terhadap luas sampel peta pendaftaran menunjukkan bahwa dari 51 sampel bidang tanah hasil digitasi citra QuickBird, hanya sebanyak 4 bidang yang ditolak, dan sisanya sebanyak 47 bidang dinyatakan diterima hasil ujinya berdasarkan syarat toleransi ketelitian luas yang digunakan. Sampel bidang yang ditolak adalah sampel bidang dengan Nomor Objek Pajak (NOP) 7 pada Blok 43, NOP 8 pada Blok 43, NOP 19 pada Blok 38, dan NOP 17 pada Blok 38. Pada bidang yang ditolak dengan NOP 17 dan 19 blok 038 disebabkan adanya kesalahan identifikasi titik batas bidang tanah. Pada bidang dengan NOP 7 dan 8 pada blok 043, disebabkan adanya perbedaan penentuan titik batas bidang pada peta pendaftaran dan digitasi citra QuickBird.

Rata-rata prosentase selisih luas hasil digitasi citra QuickBird dengan SPOP memiliki nilai 65,516 \% dimana nilai ini cukup jauh dari nilai batas toleransi sebesar $10 \%$. Hal ini disebabkan selisih luas antara hasil digitasi citra QuickBird dengan SPOP memiliki rentang interval yang besar sehingga data ini tidak dapat digunakan sebagai referensi. Nilai prosentase selisih luas pada 
syarat toleransi Surat Keputusan Direktorat Jenderal Pajak Nomor KEP-533/PJ/2000 sangat bergantung pada luas dari bidang tanah acuan, semakin luas bidang tanah acuan maka semakin besar nilai selisih luas yang dapat diterima pada prosentase selisih luas. Nilai rata-rata prosentase selisih luas dari hasil digitasi citra QuickBird yang dibandingkan terhadap luas sampel peta pendaftaran tersebut adalah 3,453. Dengan nilai rata-rata ini, maka nilai ratarata rata-rata prosentase selisih luas tersebut masuk dalam syarat toleransi berdasarkan Surat Keputusan Dirjen Pajak Nomor KEP$533 / \mathrm{PJ} / 2000$.

\subsection{Evaluasi Menurut PMNA No 3 Tahun 1997}

Evaluasi menurut PMNA 3/1997 dilakukan antara luas hasil digitasi dengan luas peta pendaftaran. Evaluasi ini dilakukan untuk mengetahui perbandingan hasil toleransi SK Dirjen Pajak yang menggunakan luas bidang dari peta pendaftaran sebagai referensi luasnya. Perhitungan dilakukan menggunakan persamaan (4) dimana selisih luas antara bidang peta pendaftaran dengan luas bidang hasil digitasi citra kurang dari sama dengan setengah akar dari luas bidang peta pendaftaran. Evaluasi nilai luas hasil digitasi citra QuickBird terhadap peta pendaftaran tanah disajikan pada Tabel 3.

$$
L_{2}-L_{1} \leq \frac{1}{2} * \sqrt{L_{1}}
$$

Keterangan :

$L_{1} \quad$ : luas bidang pada peta pendaftaran digital

$L_{2} \quad$ : luas bidang hasil digitasi citra QuickBird

Tabel 3. Hasil evaluasi terhadap peta pendaftaran berdasarkan PMNA 3/1997

\begin{tabular}{|l|r|}
\hline Jumlah Data & 51 Bidang \\
\hline Jumlah Bidang Diterima & 36 Bidang \\
\hline Jumlah Bidang Ditolak & 15 Bidang \\
\hline
\end{tabular}

Pada tabel 3 dapat diketahui bahwa sebanyak 36 sampel bidang tanah memenuhi (diterima) syarat toleransi yang diperkenankan dan sebanyak 15 sampel bidang tanah tidak memenuhi (ditolak) syarat toleransi yang diperkenankan. Bidangbidang yang ditolak pada syarat toleransi ini disebabkan adanya kesalahan identifikasi titik batas bidang tanah seperti pada bidang dengan NOP 69, 71, dan 158 pada blok 001 yang dapat dilihat pada Gambar 4 dimana titik-titik batas bidangnya tidak dapat dilihat dengan jelas dan tertutup oleh vegetasi. Hasil toleransi luas berdasarkan PMNA No 3 Tahun 1997 sangat bergantung pada luas dari bidang tanah acuan, dimana bidang tanah acuan pada sub bab ini adalah data luas bidang pada peta pendaftaran tanah. Semakin luas suatu bidang tanah maka nilai $\frac{1}{2} * \sqrt{L_{1}}$ semakin besar sehingga nilai selisih luas yang dapat ditoleransi juga semakin besar.

\subsection{Uji Statistik}

Uji $t$ dilakukan untuk mengetahui adanya signifikasi perbedaan luas antara hasil digitasi dengan luas referensi. Pada penelitian ini dilakukan uji statistik t dua pihak (two tail test) dengan tingkat kepercayaan $95 \%$ atau memiliki taraf signifikansi ( $\alpha$ ) 0,05 dengan nilai derajat kebebasan (degree of freedom) 50. Dalam uji t ini, berlaku ketentuan bahwa Hipotesis Nol (Ho) : tidak terdapat perbedan yang signifikan antara luas bidang tanah hasil digitasi citra QuickBird terhadap data luas acuan, sedangkan Hipotesis Alternatif ( $\mathrm{Ha}$ ) : terdapat perbedaan yang signifikan antara luas bidang tanah hasil digitasi citra QuickBird terhadap data luas acuan.

Tabel 4. Hasil uji t

\begin{tabular}{|l|r|r|}
\hline & \multicolumn{1}{|c|}{$\begin{array}{c}\text { Peta } \\
\text { Pendaftaran }\end{array}$} & \multicolumn{1}{|c|}{ SPOP } \\
\hline Jumlah Data & 51 Bidang & 51 Bidang \\
\hline Beda Luas Minimum & $0,190 \mathrm{~m}^{2}$ & $0.087 \mathrm{~m}^{2}$ \\
\hline Beda Luas Maksimum & $610,190 \mathrm{~m}^{2}$ & $1137.880 \mathrm{~m}^{2}$ \\
\hline $\begin{array}{l}\text { Simpangan Baku Beda } \\
\text { Luas }\end{array}$ & $98,905 \mathrm{~m}^{2}$ & $230.673 \mathrm{~m}^{2}$ \\
\hline Rata-Rata Beda Luas & $28,047 \mathrm{~m}^{2}$ & $111.161 \mathrm{~m}^{2}$ \\
\hline t hitung & 2,005 & 3,407 \\
\hline t tabel & 2,008 & 2,008 \\
\hline Hipotesis Ho & Diterima & Ditolak \\
\hline Hipotesis Ha & Ditolak & Diterima \\
\hline
\end{tabular}

Hipotesis Nol (Ho) diterima dan Hipotesis Alternatif (Ha) ditolak apabila nilai t hitung berada pada daerah penerimaan Ho (antara nilai $\mathrm{t}$ tabel negatif dan $\mathrm{t}$ tabel positif), sedangkan Hipotesis Nol (Ho) ditolak dan Hipotesis Alternatif (Ha) diterima apabila nilai $t$ hitung berada pada daerah penolakan Ho (lebih kecil dari nilai t tabel negatif atau lebh besar dari nilai t tabel positif), dengan ketentuan nilai t tabel pada kolom adalah $\alpha / 2$ dan pada baris merupakan nilai degree of freedom. Nilai $t$ hitung dihitung menggunakan persamaan 2. Pengujian statistik dilakukan antara hasil digitasi dengan luas atribut peta blok dan antara hasil digitasi dengan peta pendaftaran. Hasil dari uji statistik ini, disajikan pada Tabel 4.

Pada uji t antara digitasi citra dengan SPOP (atribut peta blok), hipotesis Ho ditolak dan Ha diterima yang artinya terdapat perbedaan yang signifikan antara luas bidang tanah hasil digitasi citra QuickBird terhadap data luas tabel atribut peta blok PBB-P2. Namun, pada uji $t$ antara digitasi citra dengan peta pendaftaran tanah hipotesis Ho diterima dan Ha ditolak yang artinya tidak terdapat perbedaan yang signifikan antara luas bidang tanah hasil digitasi citra QuickBird terhadap luas bidang tanah pada peta pendaftaran. Karena luas referensi yang digunakan pada penelitian ini adalah luas dari peta pendaftaran tanah, maka hasil yang digunakan adalah hasil dari pengujian digitasi citra QuickBird terhadap peta pendafatran.

\section{Kesimpulan}

Pendekatan partisipatif bersama para kepala dusun dan masyarakat telah diterapkan di dalam penelitian ini untuk mendeliniasi batas bidang tanah di beberapa lokasi di Desa Triharjo. Pendekatan partisipatif ini menunjukkan hasil yang cukup baik, terutama ditinjau dari aspek efisiensi dan efektfitas proses identifikasi dan deliniasi batas bidang tanah. Keterlibatan masyarakat dapat mempercepat proses identifikasi dan deliniasi batas bidang tanah didukung oleh local knowledge yang mereka miliki.

Hasil evaluasi nilai luas bidang hasil digitasi citra QuickBird menurut Surat Keputusan Dirjen Pajak Nomor KEP-533/PJ/2000 dengan menggunakan luas acuan atau referensi yang diambil dari peta pendaftaran tanah menunjukkan bahwa citra tegak satelit resolusi tinggi (CTSRT) dalam khususnya citra tegak QuickBird dapat digunakan untuk membuat peta blok PBB-P2. Pada evaluasi berdasarkan Surat Keputusan Dirjen Pajak Nomor KEP- 
533/PJ/2000 menggunakan luas referensi peta pendaftaran tanah, luas hasil digitasi citra QuickBird memenuhi syarat toleransi.

Dalam konteks percepatan updating peta blok PBB, penggunaan CTSRT sebagai peta dasar serta pendekatan partisipatif masyarakat bisa menjadi alternatif sebagai pengganti survei terestris maupun keterbatasan peta pendaftaran tanah dari BPN.

\section{Pernyataan Konflik Kepentingan}

Penulis menyatakan tidak ada konflik kepentingan dalam artikel ini(The authors declare no competing interest).

\section{Ucapan Terima Kasih}

Penulis mengucapkan terimakasih kepada Badan Keuangan dan Aset Daerah (BKAD), Dinas Pertanahan dan Tata Ruang (Dispertaru), Badan Perencanaan Pembangunan Daerah (BAPPEDA) Kabupaten Bantul yang telah menyediakan data yang digunakan dalam penelitian.

\section{Referensi}

Aditya, T., Maria-Unger, E., Berg, C., Bennett, R., Saers, P., Syahid, H. L., Erwan, D., Wits, T., Widjajanti, N., Santosa, P. B., Atunggal, D., Hanafi, I., dan Sutejo, D. (2020). Participatory Land Administration in Indonesia: Quality and Usability Assessment. Land. 9(3), 79. doi:10.3390/land9030079

Ali, Z., Tuladhar, A., \& Zevenbergen, J. (2012). An integrated approach for updating cadastral maps in Pakistan using satellite remote sensing data. International Journal of Applied Earth Observation and Geoinformation, 18(1), hal 386-398.

Alkan, M., \& Marangoz, M. A. (2009). Creating Cadastral Maps in Rural and Urban Areas of Using High Resolution Satellite Imagery. Applied Geoinformatics for Society and Environment 2009, hal 89-95.

Al-Vatia, T. V. \& Djojomartono, P. N. (2019). Analysis of the Effect of Land Use Planning and Land Value in Gamping Subdistrict, Sleman, D.I Yogyakarta from 2013 to 2018. Journal of Geospatial Information Science and Engineering, Vol. 2 No. 2 (2019). doi:10.22146/igise.51076

Anonim. (1997). Peraturan Menteri Negara Agraria/Kepala Badan Pertanahan Nasional Nomor 3 Tahun 1997 tentang Ketentuan Pelaksanaan Peraturan Pemerintah Nomor 24 Tahun 1997 tentang Pendaftaran Tanah. Badan Pertanahan Nasional.

Anonim. (2009). Undang-Undang Republik Indonesia Nomor 28 Tahun 2009 tentang Pajak Daerah dan Retribusi Daerah. Republik Indonesia: Dewan Perwakilan Rakyat.

Aristalindra, F. (2019). Evaluasi Nilai Luas Bidang Tanah Hasil Digitasi Citra Quickbird untuk Membuat Peta Blok Pajak Bumi dan Bangunan Perdesaan dan Perkotaan (PPPP2) Menurut Surat Keputusan Dirjen Pajak Nomor : Kep533/Pj/2000. Universitas Gadjah Mada.

Direktorat Jenderal Pajak. (2000). Surat Keputusan Direktorat Jenderal Pajak Nomor KEP-533/PJ/2000 tentang Petunjuk Pelaksanaan Pendaftaran, Pendataan dan Penilaian Objek dan Subjek Pajak Bumi dan Bangunan (PBB) Dalam Rangka Pembentukan dan/atau Pemeliharaan Basis Data Sistem Manajemen Informasi Objek Pajak (SISMIOP).

Lillesand, Kiefer, \& Chipman. (2014). Remote Sensing and Image
Interpretation 7th Edition. New York : John Wiley.

Nasution, R. (2003). Teknik Sampling. Universitas Sumatera Utara Diambil dari http://library.usu.ac.id. Diakses pada $20 \mathrm{Mei}$ 2019.

Rudianto, B. (2010). Analisis Ketelitian Objek pada Peta Citra Quickbird RS 0,68 m dan Ikonos RS 1,0 m. Rekayasa, Institut Teknologi Nasional, XIV(3), hal 156-164

Salkind, N. J. (2010). Encyclopedia of Research Design, Volume 1. California: Sage.

Santosa, P. B. (2016). Evaluation of satellite image correction methods caused by differential terrain illumination. Jurnal Forum Geografi. Vol. 30, No. 1 (2016). doi:10.23917/forgeo.v30i1.1768

Santosa, P. B., Subaryono, Diyono \& Pamungkas, S. D. (2016). Kondisi Data Spasial Dalam Mendukung Pelayanan Pajak Bumi dan Bangunan. Prosiding FIT ISI dan CGISE 2016. https://repository.ugm.ac.id/276114/1/33\%20Pap er\%20CGISE $\% 202016 \% 20$ Data $\% 20$ spasial $\% 20 \mathrm{~PB}$ B.pdf

Sulistyawati, M. N., Aditya, T., Santosa, P. B. (2018). Development of Spatio-Temporal Database Prototype For Management of 4-Dimensional Cadastre Object In Indonesia. Journal of Geospatial Information Science and Engineering. Vol. 1, No. 2 (2018). doi: $10.22146 /$ igise.41680

Sulistyowati, E. (2003). Kajian Ketelitian Luas Peta Blok PBB Hasil Digitasi Citra IKONOS GeoColor. Tesis. Universitas Gadjah Mada.

Tejada, J. J. and Punzalan, R. B. (2012). On the Misuse of Slovin's Formula. The Philippine Statiscian, hal. 129-136.

Watters, S. B. and P. A. (2008) Statistic in a Nutshell. California: O’Reilly Media. 